\title{
TBS en Rapportage pro Justitia Een historische beschouwing
}

\section{A.W.M. Mooij ${ }^{* *}$}

De wetswijziging in 1988 die leidde tot de naamswijziging van $T B R$ in $T B S$, heeft geleid tot een aantal problemen met betrekking tot de rapportage pro Justitia.

De belangrijkste twee elementen hierbij zijn:

- het (volgens art. 37b WvSr) vereiste van een onderzoek door twee gedragskundigen, onder wie een psychiater, voorafgaand aan een eventueel bevel tot verpleging en

- het vereiste van een onafhankelijk onderzoek, door een psychiater en psycholoog die niet aan de inrichting verbonden zijn, wanneer verlenging van de terbeschikkingstelling wordt gevorderd wanneer deze zes jaar (of een veelvoud daarvan) heeft geduurd (volgens art. $509 \mathrm{WvSv}$ ).

Het oogmerk van deze twee bepalingen is zonder meer een versterking van de rechtspositie van de TBS-gestelde dan wel van degenen die potentieel onder de werkingssfeer van de Wet op de terbeschikkingstelling vallen. De eis van een onderzoek voorafgaand aan een bevel tot verpleging beoogt uiteraard te verhinderen dat een terbeschikkingstelling opgelegd zou worden zonder dat aan belangrijke criteria (de aanwezigheid van een stoornis, de doorwerking in de delictieuze handeling, de aanzienlijke kans op herhaling etc.) zou zijn voldaan. De 'second opinion' van onafhankelijke deskundigen, naast de visie van de kliniek, zou ertoe bijdragen dat een terbeschikkingstelling niet langer zou duren dan echt noodzakelijk is. De zo ingebouwde rechtsbescherming heeft echter ook een effect dat misschien niet beoogd is, maar wel is opgetreden: de weigerende observandus. Het gaat om de verdachte die weigert medewerking te verlenen aan het psychiatrisch onderzoek, zodat er in dat geval geen advies voorligt en daarmee niet aan één der voorwaarden is voldaan wil een oplegging (of verlenging) van de terbeschikkingstelling mogelijk zijn.

*Zenuwarts, lid directie van het Pieter Baan Centrum te Utrecht en bijzonder hoogleraar Forensische Psychiatrie RU Groningen. 
Hiermee raken we de kern van het sanctiestelsel, dat in de maatregel van de terbeschikkingstelling zijn uitdrukking vindt. Beoogd wordt gestoorde en gevaarlijke individuen uit de totale som der gedetineerden te lichten om door middel van verpleging en zo mogelijk behandeling de samenleving te vrijwaren tegen risico's die zij in zich dragen. Als echter door de toegenomen rechtsbescherming iemand, die potentieel wel onder de werkingssfeer van de Wet op de terbeschikkingstelling valt, zich daaraan kan onttrekken, wordt daarmee de grondgedachte van het stelsel zelf geraakt. Afgezien van de omvang van het probleem, is de kwestie principieel van belang, omdat zij leidt naar de vraag welke mate van rechtsbescherming wetten als die van de terbeschikkingstelling kunnen verdragen, willen zij nog effectief en zinvol zijn. Het gaat in wezen om de oude en fundamentele tegenstelling tussen enerzijds de doelmatigheid van een criminele politiek van de overheid en anderzijds de rechtsbescherming, tot uiting komend in zorgvuldige besluitvorming, die dezelfde overheid heeft te bieden. Gezien het feit dat het om een fundamentele maar ook om een oude tegenstelling gaat, is het goed om het historische perspectief, zij het summier, erbij te betrekken.

\section{De klassieke richting en de forensische psychiatrie}

Er is een opvallende gelijktijdigheid tussen het ontstaan van het moderne recht en van de moderne psychiatrie: beide zijn een uitvloeisel van de Franse Revolutie. Het is immers gebruikelijk de moderne psychiatrie te laten aanvangen met de stichtingsakte van Pinel die, kort na het begin van de Franse Revolutie, de ketenen van de gestoorden wegnam en zo de psychiatrische patiënt, als psychiatrische patiënt, schiep. Zo kon het innerlijk van de psychisch zieke mens voorwerp van studie en behandeling worden van de zich ontwikkelende psychiatrie. De codificaties die in de naweeën van de Franse Revolutie tot stand kwamen richtten zich echter niet op het innerlijk maar uiterlijk van de menselijke gedraging. Deze insteek is geheel begrijpelijk vanuit de achtergrond waarbinnen de codes tot stand kwamen. De Code Pénal is duidelijk opgezet vanuit het perspectief van de rechtsbescherming, dat als reactie fungeerde op het absolutisme van de vorst dat daarvóór, grofweg gesteld, heerste.

Van te voren opgestelde en scherp omschreven delictsbepalingen die verder geen of nauwelijks interpretatie behoefden, moesten de burger vrijwaren tegen de als willekeurig ervaren criminele politiek van de vorst. 
Men denke daarbij aan de beruchte 'lettres de cachet'; respectievelijk aan het leven dat Markies de Sade moest leiden, jarenlang opgesloten dankzij de invloed van zijn schoonmoeder. Een wezenlijk element van het perspectief van de rechtsbescherming was de bescherming van de intieme levenssfeer. Het denken en voelen stond ieder vrij, alleen het handelen was, eventueel, strafbaar. Dit paste natuurlijk bij de uitkomst van het debat dat in de Verlichting was gevoerd. Dit vertrok bij de constatering van levensbeschouwelijke pluriformiteit, een verlies van eenstemmigheid in de beantwoording van de vraag hoe het leven in te richten. Het kwam uit bij de slotsom dat de overheid niet tot taak had een particuliere levensvorm ingang te doen vinden, maar zich moest beperken tot het bewerkstelligen van een maatschappelijk arrangement waarbij iedere burger maximale vrijheid geniet om het leven naar eigen voorkeur in te richten. Bij deze burgerlijk liberale ethiek, die sedertdien dominant is geworden, past een strafrechtelijke uitwerking waarin plaats is voor een maximale bescherming van de intieme levenssfeer. Op strafrechtelijk terrein leidt dit tot een daadstrafrecht, in die zin dat het accent komt te liggen op sterk veruitwendigende delictsomschrijvingen.

Deze daadgerichtheid beperkte sterk de armslag van die discipline die psychiatrie en recht verenigt, de forensische psychiatrie. Deze beperking weerspiegelt zich duidelijk in het artikel 64 van de Code Pénal waar staat: 'Il n'y a ni crime ni délit, si le prévenu était en état de démence au moment de l'action, ou lorsqu' il a été contraint par une force à la quelle il n'a pu résister'. Letterlijk genomen gaat het hier niet om de vraag of de daad al dan niet is toe te rekenen, dan wel of de dader ontoerekeningsvatbaar is. Een dergelijke vraag reeds zou een verschuiving inhouden van de daad naar de dader, welke beweging, in ieder geval door de wettekst zelf, wordt tegengegaan. Er is blijkbaar voor een sterkere formulering gekozen. In voorkomende gevallen is er 'ni crime, ni délit', waarbij de in aanmerking komende voorwaarden beperkt blijven tot de vermelde twee. Deze daad-gerichtheid blokkeerde een meer dader-gerichte benadering en stond derhalve de ontwikkeling van de forensische psychiatrie in de weg, die uiteraard meer in de dader achter de daad dan in de daad zelf was geïnteresseerd. Tevens bemoeilijkte de retrospectieve gerichtheid van de klassieke richting het voeren van een op de toekomst en op toekomstig gedrag gerichte criminele politiek. Dit is begrijpelijk omdat de klassieke richting overheidsingrijpen in de privé-sfeer zoveel mogelijk wilde beperken en de grond en de begrenzing daarvan slechts zag liggen in een voorafgaande verstoring van de orde (door het delict). Hier is ook weer de reactie te bespeuren op de afwijzing van een als willekeurig ervaren criminele politiek van de vorst. 


\section{De nieuwe richting en de forensische psychiatrie}

De nieuwe richting is te zien als een antwoord op de problemen die door de klassieke richting, met haar accent op rechtsbescherming en beperking van overheidsingrijpen, zijn opgeroepen, en met name door de beperkingen waartoe zij noodzaakte. De nieuwe richting kwam voort uit de behoefte wel een op toekomstig gedrag van de justiabele gerichte criminele politiek te kunnen voeren. Het accent ligt niet langer op de rechtsbescherming maar op de mogelijkheid te komen tot een doelmatige bestrijding van de misdaad, waartoe het strafrecht een instrument moest worden. Het strafrecht zou daarbij gebruik kunnen maken van de zich ontwikkelende sociale en gedragswetenschappen. Bovendien waren de sociale tegenstellingen, door industrialisatie en proletariaatsvorming, zodanig groot geworden dat ook van hieruit zich de behoefte aan ruimere mogelijkheden om strafrechtelijk in te grijpen, deed gevoelen. Het ging niet meer om de bescherming van de (gegoede) burger tegen de willekeur van de vorst - die strijd was gestreden maar om de bescherming van de maatschappij tegen gevaarlijke individuen. Maar wil men die taak op zich nemen, dan dient er ook kennis te zijn van die potentieel gevaarlijke individuen. Zo vindt hier de paradigma-wisseling van het klassieke, retrospectieve, daad-gerichte strafrecht, naar een nieuw prospectief, dader-gericht strafrecht zijn beslag.

Het is duidelijk dat de nieuwe richting met haar dader-gerichtheid de forensische psychiatrie een grotere armslag bood. Het juridisch kader van de nieuwe richting maakte de bloei van de forensische psychiatrie mogelijk, zoals de klassieke richting het ontstaan ervan mogelijk maakte. Maar zoals de klassieke richting met haar daad-gerichtheid de forensische psychiatrie tegelijkertijd kortwiekte, leidde het juridisch kader van de nieuwe richting tot haar bloei. Binnen dit kader konden de (forensische) gedragswetenschappen zich ontwikkelen. Een individualiserende benadering werd mogelijk, welke leidde tot de mogelijkheid gradaties in de toerekeningsvatbaarheid aan te nemen. En ook de humanisering in de straftenuitvoerlegging is een uitvloeisel van de nieuwe richting. Zo vertoont de nieuwe richting een Janus-kop. Zij biedt de mogelijkheid tot individualisering en humanisering in de benadering van de, psychisch gestoorde, delinquent. Maar daarmee wordt ook de mogelijkheid geboden tot een vergaande penetratie in de intieme levenssfeer, waarvan de klassieke richting, vanuit het idee van de rechtsbescherming, zich verre hield. Deze tot individualisering en humanise- 
ring leidende penetratie in de intieme levenssfeer werd gelegaliseerd door het idee van de bescherming van de samenleving tegen gevaarlijke individuen.

De TBR-wetten zijn, ongeacht de gesloten compromissen in het traject van de wetgevingsgeschiedenis, te zien als een typisch geestelijk kind van de nieuwe richting. In het kader van een extreme sanctie, een detentie van in principe onbepaalde duur, is een individualiserende en humane bejegening van de psychisch gestoorde justitiabele mogelijk geworden. TBR, thans de TBS, is zo bezien een paradox. Vanuit een beheersingsideaal is individualisering en humanisering mogelijk, welke ook niet geëffectueerd kunnen worden indien er geen zichtbaarmaking van de intieme levenssfeer plaatsvindt. Een uitvloeisel hiervan is wel dat de TBR-wetten, gezien hun herkomst en aard, niet zo veel rechtsbeschermend potentieel kunnen bevatten. Dit leidt dan tot de vraag welke mate van rechtsbescherming dit soort wetten kan verdragen, willen zij nog zinvol zijn.

\section{De TBS-wet van 1988}

Deze vraag heeft hernieuwde actualiteit gekregen sedert de invoering van de nieuwe Wet op de terbeschikkingstelling in 1988. Deze wetswijziging had tot doel, zoals hierboven geschetst, de rechtsbescherming van de terbeschikkinggestelde, alsmede van degenen die - nog niet terbeschikkinggesteld - wel potentieel onder het bereik ervan vallen, te vergroten. Belangrijke elementen daartoe waren - zoals vermeld - de eisen van een psychiatrisch onderzoek voorafgaand aan een oplegging van een terbeschikkingstelling en bij de zogenaamde zesjaars verlenging. Hiermee is de bescherming van de potentieel terbeschikkinggestelde aanzienlijk versterkt, omdat de weigering om een psychiatrisch onderzoek te ondergaan, de feitelijke oplegging van een terbeschikkingstelling onmogelijk zou kunnen maken. Dit is echter weer in strijd met de grondgedachte van de nieuwe richting ter zake, die juist door middel van wetgeving de mogelijkheid wilde bieden om gevaarlijke subjecten duurzaam uit de samenleving te verwijderen. Ook een zekere toepassing van het proportionaliteitsbeginsel - duur van de vrijheidsbeneming dient in overeenstemming te zijn met de ernst van het initiële strafbare feit - leidde tot beperking van het eliminerend vermogen van de TBS. 


\section{Hoe verder?}

Deze problematiek zal benaderd moeten worden vanuit de huidige situatie zoals deze historisch is gegroeid. Dat betekent dat men zich moet realiseren dat een verabsolutering van de idee van de rechtsbescherming zal leiden, op termijn, tot een ontmanteling van de instellingen die in de lijn van de nieuwe richting tot ontwikkeling zijn gekomen. Het zal het einde van het TBS-veld inluiden met inbegrip van de sterk op individualisering gerichte bejegening van psychisch gestoorde delinquenten.

Een verabsolutering van het beheersingsideaal zal echter leiden tot uitholling van het rechtsbeschermend potentieel dat in de TBS-wet nog aanwezig is.

Dit klemt te meer omdat een forensisch psychiatrisch onderzoek en a fortiori de oplegging van een terbeschikkingstelling een zeer sterke inbreuk op de intieme levenssfeer inhoudt, waarover men niet licht moet denken. Dit leidt ertoe dat men voortdurend de balans in het oog zal dienen te houden tussen de doelmatigheid van de betreffende maatregel enerzijds en het optimum aan rechtsbescherming voor de justiabele anderzijds. Doet men dit niet dan zal men vervallen tot een misplaatste verabsolutering van de rechtsbescherming, die de verworvenheden van de nieuwe richting verloren laat gaan, dan wel tot een ongebreideld instrumentalisme dat de psychische intimiteit bruuskeert en daarmee een culturele verworvenheid overboord zet.

\section{Gedwongen psychiatrisch onderzoek?}

In deze situatie staan verschillende mogelijkheden open. Men zou een weigeringsrecht, dat impliciet in de wet van 1988 staat, expliciet kunnen honoreren. Of men zou het weigeringsrecht expliciet kunnen verlenen, maar buiten werking kunnen stellen in bepaalde zeer ernstige gevallen. Een derde mogelijkheid betreft een brede buitenwerkingstelling in alle gevallen van weigering een dergelijk onderzoek te ondergaan. De eerste mogelijkheid leidt tot een karakterwijziging van de TBS-wet, om redenen die hierboven zijn aangegeven. De laatste twee mogelijkheden leiden tot de vraag van een gedwongen onderzoek.

Ten aanzien van een eventueel gedwongen onderzoek geldt echter dat het weer haaks staat op de gedachte van de bescherming van de intieme levenssfeer, die een bijzonder centrale waarde vertegenwoordigt, zowel in de wijze zoals het moderne recht zich heeft vormgegeven, als in de wijze waarop deze 
waarde gedurende de laatste decennia, met hun accent op de rechten van de mens - neergelegd in internationale verdragen - nog in aanzien is gestegen. Daarbij komt dat het gedwongen psychiatrisch onderzoek, in tegenstelling tot wat soms gedacht wordt, zeer moeilijk uitvoerbaar is, omdat het bij de vraag naar de aanwezigheid van een stoornis respectievelijk de doorwerking daarvan in een tenlaste gelegde feit, veelal niet gaat om zichtbaar gestoorde gedragingen maar om een innerlijke stoornis in de wijze van beleven, in de interpretatie van de werkelijkheid en in de vormgeving van het handelen. De taxatie binnen deze domeinen vereist bij uitstek 'penetratie' in de innerlijke levenssfeer, en daartoe is bereidheid van de verdachte enige 'opening' te geven, bij voorbeeld door gespreksbereidheid te tonen, noodzakelijk. Het is slechts in uitzonderingen mogelijk, bij voorbeeld bij zeer ontremd psychotisch gedrag, alleen op grond van uitwendig waarneembare gedragingen te komen tot een gegronde taxatie van stoornis en doorwerking daarvan in een strafbaar feit.

In ieder geval lijkt het nodig om, wanneer men zou koersen naar een gedwongen onderzoek, formele en materiële bepalingen te formuleren. Vanuit het grote belang van de waarde van de bescherming van de intieme levenssfeer en de grote inbreuk daarop door een gedwongen onderzoek, lijkt een daartoe strekkend besluit genomen door slechts een rechter-commissaris in het kader van een gerechtelijk vooronderzoek, te licht. Tevens zou bepaald moeten worden wat een onderzoek inhoudt respectievelijk waarop een onderzoek ten minste moet berusten. Het komt mij voor dat een onderzoek 'op stukken' - dat wil zeggen: onderzoek dat niet betrekking heeft op de betrokkene zelf maar op materiaal dat door anderen over betrokkene is aangeleverd - in ieder geval niet volstaat.

Daarnaast zal de noodzaak van gesprekken opgevoerd moeten worden, omdat het gesproken woord toch het medium is om toegang tot het innerlijk beleven te verkrijgen en tevens middel is om enige toetsing van de eigen hypothesen aangaande de belevingssfeer van de verdachte mogelijk te maken. Tenslotte zal er gewerkt moeten worden aan een summiere observatiecode. Deze code zal iets formuleren omtrent de wijze van bejegening van de verdachte in het kader van een gedwongen onderzoek. Hem zal in ieder geval duidelijk moeten worden gemaakt wat het bereik van de gedragsobservatie is - eventueel dat dit bereik niet begrensd is en dat ook een gesprekje dat door verdachte als ondersteunend kan worden beleefd, toch de observatie dient. Juist de afhankelijke positie waarin een justitiabele in deze context verkeert, maakt dat het verschaffen van duidelijkheid een absolute vereiste is. Het mag niet zo zijn dat, wanneer de grens van een gedwongen 
onderzoek gepasseerd is, een ongeclausuleerde inbreuk op de intieme levenssfeer gelegitimeerd zou zijn. Ook zo'n penetratie dient genormeerd te worden.

\section{Beschouwing}

Hiermee is niet gepleit voor een gedwongen psychiatrisch onderzoek voorafgaand aan een eventuele oplegging van een terbeschikkingstelling. Wel is gepleit tegen een ongeclausuleerd gedwongen onderzoek. De discussie overschrijdt het belang van de zaak zelf omdat, bij een volledig ongeclausuleerd weigeringsrecht, de overheid wellicht haar belangstelling voor de terbeschikkingstelling zou gaan verliezen; de maatregel zou dan immers principieel niet meer aan haar doelstelling kunnen beantwoorden. De gevolgen daarvan zijn, in meer praktische zin, het prevaleren van een daad-gericht strafrecht, het meer opleggen van langere gevangenisstraffen, het terugtreden van de forensische psychiatrie en het verdwijnen van wat zij heeft mogelijk gemaakt. Anderzijds heeft de overheid ook een natuurlijke belangstelling voor een maatregel als de terbeschikkingstelling. De tenuitvoerlegging ligt immers voor een deel in handen van de regering; daarmee is het voeren van een effectief strafrechtelijk beleid, al dan niet casus-gericht, in beginsel mogelijk.

Zoals immer is een genuanceerde houding en een afstandelijke verhouding onontbeerlijk in het complexe veld van psychiatrie en recht. Een zekere alertheid is daarbij ook nodig omdat de relatie van de forensische psychiatrie met de overheid de facto nauwer is dan met de rechterlijke macht, waarmee de relatie in principe afstandelijk is. Het risico is dan aanwezig dat gehoor gegeven kan worden aan de wensen van de overheid op een bepaald moment.

De forensische psychiatrie beschikt echter, voor zover zij als psychiatrie optreedt, over eigen waarden, welke waarden niet strijdig zijn met fundamentele rechtswaarden. Een fundamentele rechtswaarde binnen het moderne recht, zoals het zich sedert de Franse Revolutie heeft vormgegeven, betreft de bescherming van de intieme levenssfeer. De moderne psychiatrie is merkwaardig genoeg - zoals hierboven is aangegeven - in dezelfde tijd ontstaan als het moderne recht. Beide disciplines ontstaan in de Franse Revolutie en in de naweeën ervan, en hun gemeenschappelijke waarde betreft het respect voor de intieme levenssfeer. Het recht heeft hierbij de taak bescherming van het psychische tegen politieke machtsuitoefening te bieden, en aan de psy- 
chiatrie valt de zorg voor het psychische toe. Als gemeenschappelijke waarden hebben dan psychiatrie en recht: het respect voor de intimiteit, voor de psychische realiteit.

Zo kunnen zowel vanuit een evenwichtig rechtsbegrip, als vanuit een psychiatrie die haar eigen waarden onderkent, kritische vragen worden gesteld bij elk instrumentalisme, van waaruit de psychische realiteit niet meer voldoende beschermd en daarmee gebruuskeerd wordt, maar ook bij een verabsolutering van de waarde van de rechtsbescherming, in het spoor waarvan men van de psychische intimiteit niets meer weten mag. Historisch besef kan daarbij helpen. Zonder historisch besef, dat leidt tot inzicht in eigen waarden, is de forensische psychiatrie een gemakkelijk slachtoffer - wellicht zonder dat zij dit zelf beseft - enerzijds van tendensen die vanuit een verabsolutering van de waarde van de rechtsbescherming kunnen leiden tot haar terugtred, en anderzijds van behoeften tot het voeren van een criminele politiek, die haar kunnen doen terugvallen tot niet meer dan een instrument van die criminele politiek.

\section{Nawoord: 1990 - 1995}

De problematiek van de TBS in samenhang met de rapportage pro Justitia bleef ook na wetswijziging van 1988 aandacht vragen. Dit is niet verwonderlijk, gezien de fundamentele vragen die hier spelen op het vlak van de rechtswaarden en de praktische moeilijkheden die zich deden gevoelen bij de berechting van de verdachte die medewerking weigerde te verlenen aan een psychiatrisch onderzoek. De meningen waren vooreerst verdeeld over de vraag of een weigering een onderzoek te ondergaan het opleggen van een TBS definitief onmogelijk zou maken, totdat de Hoge Raad in 1993 stelde dat een weigering van een verdachte mee te werken het de rechter niet onmogelijk zou maken een verpleging van overheidswege te bevelen. Inmiddels zijn er twee wijzigingen in de regelgeving omtrent de TBS en rapportage doorgevoerd. De eerste wijziging heeft betrekking op de artikelen 196 en 198 WvSv, volgens welke het Pieter Baan Centrum als een inrichting voor klinische observatie in de zin van art. 198 werd aangemerkt. Grondwettelijke belemmeringen (art. 10 lid 1 G.W. en art. 11 G.W.), met betrekking tot eerbiediging van de persoonlijke levenssfeer en de integriteit van het eigen lichaam die een gedwongen observatie in de weg stonden, waren daarmee weggenomen. Tevens werd hiermee een beroepsregeling, die in de 
onderhavige artikelen vervat ligt, van toepassing op een eventuele gedwongen observatie.

Aan de onzekerheid of bij weigering een onderzoek te ondergaan toch een TBS kon worden opgelegd, werd een eind gemaakt door de wetswijziging (22909) die op 15 januari 1994 van kracht werd. De eis van een advies blijft buiten toepassing indien de verdachte weigert mee te werken aan een onderzoek. Deze wetswijzigingen bracht ook enkele kleine technische modificaties. De geldigheidsduur van het onderzoek werd verlengd van een half tot een heel jaar, aangezien de aanvankelijke termijn bij de behandeling in hoger beroep nogal eens voor problemen zorgde. Het vereiste van een onafhankelijk onderzoek door een psychiater en een psycholoog die niet aan de inrichting verbonden zijn, wanneer de verlenging van de terbeschikkingstelling wordt gevorderd wanneer deze zes jaar (of een veelvoud daarvan) heeft geduurd, werd vervangen door het vereiste van een onderzoek door een psychiater en gedragskundige. Dit zijn enkele technische punten van ondergeschikt belang, zodat mede op grond daarvan deze wetswijziging als een reparatie-wet is gezien. Toch lijkt deze kwalificatie, inhoudelijk bezien, niet juist. Het oogmerk van de wet van 1988, geschreven vanuit het perspectief van de rechtsbescherming, was te verhinderen dat er een TBS opgelegd zou worden als niet aan bepaalde voorwaarden van zorgvuldigheid was voldaan, blijkend uit het vereiste van het voorliggen van een advies. Die eis is komen te vervallen. Daarmee is toch de kern uit de oorspronkelijke wet gehaald. De oorspronkelijke wet bouwde waarborgen in voor de verdachte die er op grond van een andere belangenoverweging, stammend uit de behoefte een effectieve criminele politiek te kunnen voeren, weer zijn uitgehaald. De slinger tussen de polen van rechtsbescherming en het voeren van een effectieve criminele politiek, sloeg in een kort tijdsbestek van slechts enkele jaren door, van de ene pool naar de andere.

Hoewel de leer nu niet meer geschreven is vanuit het perspectief van de rechtsbescherming, is de praktijk een goede leerschool. De Memorie van Toelichting tempert meteen de verwachtingen omtrent de uitkomst van een psychiatrisch onderzoek bij een verdachte die consequent weigert aan een onderzoek medewerking te verlenen, en stelt dat in zulk een geval de weigering gerespecteerd zou moeten worden (p. 11).

Er moet dan een rapport gemaakt worden over zijn verblijf in de observatieinrichting en over de motieven van zijn weigering indien daar inzicht in is verkregen.

De nieuwe wet van 1994 biedt dan echter, theoretisch, wel de mogelijkheid alsnog een TBS op te leggen. In dat geval zal echter de rechter zelfstandig 
een oordeel moeten vellen over de aanwezigheid van een stoornis, de psychiatrische aspecten van de toerekening, toekomstig gevaar voortkomend uit de stoornis en de vraag of dit gevaar niet op andere wijze kan worden afgewend. Het spreekt vanzelf dat deze vragen niet eenvoudig te beantwoorden zijn; de vragen vormen op zich reeds een belemmering voor een te voortvarende oplegging van een TBS. Het verschil is wel dat, waar vroeger in zekere mate een wettelijke waarborg gold, thans na 1994 de waarborg geboden wordt door rechterlijke prudentie welke uiteraard ook van grote betekenis is. Hierbij doet zich uiteindelijk de vraag voor naar de zin van dit genre van voortdurende wetgeving, waarbij in de doctrine de veranderingen groot zijn, maar in de praktijk die veranderingen zich niet weerspiegelen. Deze korte historie, van 1990 tot 1995, kan ons in ieder geval leren dat de praktijk weerbarstiger is dan de leer. Dit is zeker het geval als de doctrine niet dóórdenkt. Een zeker accent op de rechtsbescherming in wetgeving heeft als schrikreactie een versterking van de behoefte aan het voeren van effectieve criminele politiek gegeven. Het resultaat in wetgeving kan echter door beperkingen die gegeven zijn met rechterlijke prudentie maar zeer ten dele worden benut voor het doel dat beoogd wordt. Historisch besef dat oog heeft voor de fundamentele waarden die hier spelen met een daarbij behorend evenwichtig rechtsbegrip, had wellicht de recente wetgevingsgeschiedenis overbodig gemaakt. Nu dit niet het geval is geweest, is het nut van de recente geschiedenis wellicht hierin gelegen dat zij ons nog eens confronteert met een basaal gegeven: het nut van historisch besef en van een daarbij behorend evenwichtig rechtsbegrip als zodanig. 